\title{
Hacia una nueva conceptualización evolutiva de la comunicación «cultural»
}

\author{
Communicating Culture: An Evolutionary Explanation
}

\begin{abstract}
RESUMEN
Ya sea reunidos alrededor de una fogata, viendo TV o sentados frente a la pantalla del computador, las presiones de la selección natural darwiniana han forzado a los individuos a ceñirse a cerrados patrones de interdependencia, los que a su vez han sido estructurados mediante lazos comunicacionales. ¿Puede ser analizado este hábito de compartir información de nuestra especie desde una perspectiva más amplia y, eventualmente, fomentar una mayor armonía para toda la Humanidad? Los autores sostienen que la respuesta a esta pregunta es afirmativa. La cultura proporciona el espacio necesario para la negociación y el cambio social, y la habilidad de comunicación avanzada es el medio por el cual este trabajo cultural necesario se logra perpetuamente. Una comprensión no-determinista de la cultura debe ser reconocida desde el principio. La vida cultural difiere mucho de las condiciones biológicas; incluso bajo circunstancias represivas, la cultura no evoluciona de la misma manera que las infecciones virales devastan los cuerpos biológicos o los ordenadores. Así los avances tecnológicos en la comunicación simplemente no refuerzan e intensifican verticalmente los mensajes culturales dominantes, como sostienen las teorías del imperialismo, la transmisión memética, o el contagio social. La marcha del desarrollo cultural, durante los pasados 10.000 años, ha sido particularmente rápida, comparada con cualquier otro lapso desde que los homínidos se separaron de nuestro común ancestro con los chimpancés, hace millones de años. La habilidad única de nuestra especie como comunicadora, en el dinámico entorno tecnológico y cultural actual, es una esperanza real para recuperar las afinidades primordiales que nos unen como seres humanos.
\end{abstract}

\section{ABSTRACT}

Whether gathering around bonfires, watching TV, or sitting in front of computer screens, the pressures of Darwinian natural selection have forced individuals into tight patterns of interdependency, welded together by communication links. Can the information-sharing behavior of our species ever be brought into broader perspective and eventually foster greater harmony for all humankind? The authors argue that the answer to this question is «yes». Culture provides the necessary space for social negotiation and change. Advanced communication ability is the means by which this necessary cultural work is perpetually accomplished. A non-deterministic understanding of culture must be acknowledged from the outset. Cultural life differs greatly from biological conditions. Even under repressive conditions, culture is not determined the same way viral infections ravage biological bodies or computers. Technological advances in communication do not simply reinforce and intensify top-down, dominant cultural messages as theories of imperialism, memetic transmission, or social contagion contend. The pace of cultural development over the past 10,000 years has been particularly fast compared to any other time since hominids split from our common ancestor with chimpanzees millions of years ago. Our species' unique skill as communicators in the dynamic technological and cultural environment of today offers real hope for retrieving the primordial affinities that unite us all.

\section{PALABRAS CLAVE / KEYWORDS}

Evolución, comunicación evolutiva, cultura, transmisión cultural, desarrollo cultural.

Evolution, evolutionary communication, culture, meme, cultural transmission, cultural development.

$$
\begin{aligned}
& \text { - Dr. James Llul es Profesor Emérito del Departamento de Estudios de la Comunicación, en la Universidad Estatal } \\
& \text { de San José en California (USA) (jameslull@aol.com). } \\
& \text { Dr. Eduardo Neiva es Profesor del Departamento de Estudios de la Comunicación en la Universidad de } \\
& \text { Alabama-Birmingham (USA) (neiva@ @uab.edu). }
\end{aligned}
$$




\section{Comunicando cultura: explicación evolucionista}

«Eres el líder de un poblado primitivo. iSi quieres sobrevivir en un mundo hostil, tienes que evolucionar! En 'Las aventuras de Darwin' conducirás la evolución de tu poblado desde un pequeño grupo de simples primates a una poderosa e inteligente colonia de humanos. Lleva tu tribu a la aventura, enséñales a cazar, enséñales a edificar y enséñales el simple poder de la palabra». Este videojuego, de Sony PlayStation, estimula a los jugadores, muchos de ellos en sus primeros años de formación, para que vean el mundo con ojos evolucionistas ${ }^{1}$. De un modo simple pero convincente, el juego realza la importante ligazón entre las emergentes formas de organización social y la «empoderadora» fuerza de la comunicación humana. Con el paso de los milenios, nuestros ancestros adquirieron una inigualable habilidad para compartir información, formar y mantener relaciones sociales, innovar, y desarrollar civilizaciones y culturas avanzadas porque nos convertimos en los más diestros comunicadores sobre la Tierra.

Conducidos por la inexorable presión de la selección natural y sexual, los modos emergentes de comunicación humana encaminaron la evolución en direcciones productivas y aceleraron la velocidad del cambio social y cultural. La complejidad de la comunicación evolucionó con la complejidad social. Dos factores motivaron la sinergia: 1) la habilidad comunicativa hizo posible la interacción social de alto nivel; 2) la interacción social efectiva incrementó en gran medida las posibilidades de sobrevivencia de un organismo. Las características definitorias de la civilización moderna se desarrollaron en razón de las ventajas evolutivas posibilitadas por el lenguaje y otras formas de rasgos comunicativos avanzados, «tal vez la única distinción clara entre los seres humanos y otras especies» ( $\mathrm{Wa}$ de, 2006). Pero esto no fue siempre así. Una progresión fortuita de mutaciones biológicas y cambios conductuales con el tiempo dotaron a los humanos de la capacidad de expresarse de maneras sofisticadas y coordinar sus esfuerzos por sobrevivir. Este desarrollo ayudó a cambiar el estatus de nuestra especie de ser carroñera y fácil presa de las bestias más grandes y rápidas, convirtiéndose en un depredador innovador y exitoso. Posteriores variaciones beneficiosas condujeron a ventajas ulteriores y tal proceso continúa. Cada estadio mayor en el desarrollo de la comunicación humana representa una transición evolutiva vital (Maynard Smith \& Szathmáry, 1995).

\section{Desde dentro, desde fuera}

Ya fuera reunidos alrededor de una fogata, mirando TV o sentados frente a las pantallas de los compu- tadores, las presiones de la selección y los requerimientos biológicos de la reproducción obligaron a los individuos a establecer cerrados patrones de interdependencia integrados por lazos de comunicación. ¿Pueden tales lealtades productivas, ya probadas en el tiempo, ser alguna vez llevadas hacia una perspectiva mayor y eventualmente ser superadas en orden a proporcionar mayor armonía para toda la humanidad?

Los genes se replican. Las personas imitan. Los genes no piensan sobre lo que están haciendo. Las personas, presumiblemente, sí piensan. La naturaleza y la cultura no constituyen esferas separadas de vida; la cultura surge de la naturaleza. Pero los procesos de cambio biológico y cultural difieren de modos fundamentales e importantes. En eso reside la esperanza.

La replicación biológica es comparativamente directa. Entre las especies sexuales, la información genética pasa de los padres a los descendientes bajo la forma de secuencias de ADN y la transmisión tiene lugar solo una vez, en el momento de la concepción. Una vez que la semilla es plantada, la naturaleza hace el resto del trabajo. El éxito del organismo depende ampliamente de la tolerancia física y las cualidades nutrientes de los padres, especialmente las hembras, y la absoluta buena suerte. En este sentido, la herencia biológica es pasiva. Por otra parte, la transmisión cultural ocurre cuando la información que existe fuera de los organismos biológicos pasa de una generación a la siguiente a través de la comunicación social. El proceso es mucho menos directo que la replicación genética. Mientras las mutaciones biológicas son al azar y seleccionadas "post hoc», las elecciones culturales son motivadas desde el comienzo.

La cultura prevalece dificultosamente. Resiste el cambio, especialmente en el corto plazo, pero no está grabada sobre piedra. Por el contrario, «la cultura proporciona el espacio necesario para la negociación y el cambio. La habilidad de comunicación social avanzada es el medio a través del cual esta obra se cumple». Algunas ideas desarrollan funciones evolutivas más efectivamente que otras. Finalmente esas ideas serán seleccionadas. La evolución cultural dirigida -o el desarrollo cultural- opera con el poder de la reflexión consciente y la razón.

Nuestros entes biológicos no están determinados por los genes y nuestros entes culturales no son dictados por la tradición. Siguen un curso inexplorado, adaptándose a entornos también cambiantes, en un proceso interminable de retroalimentación biocultural (Johanson \& Edgar, 2006). Como Geertz (1973: 48) lo describió, uentre el patrón cultural, el cuerpo y el cerebro, fue creado un sistema de retroalimentación 
positiva en el que cada cual configuró el progreso del otro». Los genes compusieron extensiones de ADN que contienen instrucciones para fabricar moléculas de proteína ${ }^{2}$. Funcionan como una fórmula para el crecimiento y el comportamiento biológico. Los ingredientes y el proceso de conocimiento, sin embargo, son aportados por el entorno (Richerson \& Boyd, 2006: 9).

La interacción genes-cultura puede, incluso, ayudar a explicar uno de los grandes misterios de la conducta humana: "cómo las disposiciones psicológicas de los individuos y los patrones culturales internos de los grupos dan forma a la conciencia e impulsan a las personas a actuar de maneras específicas ${ }^{3}$. La conducta humana parece cambiar en el tiempo desde lo que es aprendido por medio de la observación a algo que es programado y almacenado en el cerebro mediante un aprendizaje de asimilación genético» (Pinker \& Bloom, 1990). Estas conductas que proporcionan una ventaja en cuanto a adaptación serán repetidas y seleccionadas. Entonces, la estructura genética resultante refleja el comportamiento inculcado y ayuda a dirigir su despliegue futuro.

Como lo señala Pinker (2009: 26), un proponente clave de esta idea, «los genes no pueden forzar directamente las palancas de nuestra conducta. Pero afectan el cableado y el desempeño del cerebro, y el cerebro es el centro de nuestros impulsos, temperamentos y patrones de pensamiento». El hecho que una persona tenga una tendencia genética heredada a la obesidad, por ejemplo, no significa que el individuo se convertirá en un obeso. El entorno también contribuye al modo cómo se desarrolla la conducta pero, en palabras de Pinker, «el entorno no es una máquina de estampados que nos estampa una determinada forma, sino un autoservicio de opciones al que nuestros genes y nuestras historias nos llevan para escoger» (Pinker, 2009: 29).

\section{3. «Memes»}

Hace treinta años, Richard Dawkins adelantó la idea de que las unidades básicas de la vida orgánica explican los logros evolutivos de largo plazo: «Están en usted y en mí; nos crearon, nuestro cuerpo y nuestra mente, y su preservación es la razón última de nuestra existencia. Vienen de mucho tiempo, estos replicadores. Ahora los conocemos por el nombre de genes, y somos sus máquinas de supervivencia».

El título de su libro, «El gen egoísta», revela el argumento de Dawkins. En vez de considerar la evolución humana desde el punto de vista de los organismos individuales o los grupos particulares que han sobrevivido, debiéramos pensar la evolución desde la perspectiva de los genes que se han transmitido de generación en generación por milenios. Por supuesto, la herencia biológica y los genes solos no explican la totalidad de la evolución humana. Enfrentando este tema en el mismo volumen, Dawkins introduce brevemente el «meme» como un modo de conceptualizar, si

\section{Una progresión fortuita de mutaciones biológicas y cambios conductuales con el tiempo dotaron a los humanos de la capacidad de expresarse de maneras sofisticadas y coordinar sus esfuerzos por sobrevivir. Este desarrollo ayudó a cam- biar el estatus de nuestra especie de ser carroñera y fácil presa de las bestias más grandes y rápidas, convirtiéndose en un depredador innovador y exitoso.}

no explicar completamente, la presencia, proliferación y atracción de ciertos temas y rasgos culturales. Se trata de un tema profundo. ¿Por qué algunas ideas culturales inspiran una perdurable y extendida aceptación y utilidad? Dibujando ilustrativos paralelos entre la replicación genética y la transmisión cultural, Dawkins especula cómo las ideas culturales podrían establecer y mantener su influencia:

«Así como los genes se propagan ellos mismos en el equipaje genético saltando de un cuerpo a otro a través de los espermas o los huevos, así los «memes» se propagan ellos mismos en el equipaje de «memes» saltando de cerebro en cerebro a través de un proceso que, en el amplio sentido, puede llamarse imitación» (Dawkins, 1989: 192).

Desde la publicación de la referencial obra de Dawkins, el «meme» ha hallado un lugar en el razonamiento científico y en el idioma inglés. El diccionario inglés Oxford define un «meme» como «un elemento de la cultura que puede considerarse que es transmitido por medios no-genéticos, especialmente por imita- 
ción». Algunos cientistas sociales hablan de «memes» cuando describen la rápida circulación de los fenómenos culturales. El «meme» se ha filtrado en la cultura popular contemporánea. El «meme» es un breve, pegajoso y práctico descriptor de una idea enorme y difícil de manejar.

Su atractivo, no obstante, puede llevarnos a engaño. El propio Dawkins no cree que los «memes» se parezcan precisamente a los genes o que cualquier teoría de los «memes» explique adecuadamente cómo ocurre la transmisión cultural. La replicación genética no es lo mismo que la imitación social. Dawkins (2006a: 191) explica que «no estoy diciendo que los 'memes' sean necesariamente análogos de los genes, sino solo que cuanto más se parecen a los genes, mejor

afectan la conciencia? El filósofo estadounidense Dennett (1995) sostiene que la transmisión de ideas culturales de una persona a otra corresponde al modo en que los organismos multicelulares comenzaron a aparecer. Aunque los científicos todavía tienen que explicar con certeza cómo aparecieron en la Tierra los organismos multicelulares, la mejor hipótesis es que varios parásitos invadieron y habitaron los organismos unicelulares originales en tanto se reproducían asexuadamente en el caldo primario. Esta fusión de organismos unicelulares dio origen a la simbiosis biológica y engendró los primeros signos de vida multicelular. Dennett sugiere que esta misma clase de patrón evolutivo ha estructurado el modo cómo los «memes» invaden y se acumulan en las mentes humanas. Un proceso de asimilación posibilita la transferencia de elementos culturales de una persona a otra, llevando a la creación de temas culturales diseminados. El «meme», según la frase memorable de Dennett (2009), es «una es tructura de datos con actitud».

La psicóloga británica Susan Blackmore define la existencia real de las culturas modernas como «el legado de miles de años de evolución mémica» (Blackmore, 1999: 182). Los «memes» «son instrucciones para actuar, almacenadas en los cerebros», argumenta, igual como «los genes son instrucciones para fabricar proteínas, almacenadas en las células del cuerpo» (Black-

funciona la teoría de los 'memes'». Él propone el concepto de "meme» como una manera de describir un agente reproductivo capaz de esparcir ideas y producir patrones culturales. Más de treinta años después de introducir el concepto, Dawkins (2006b) aclara otra vez que «nunca quiso proponerlo como una teoría de la cultura humana sino, casi como un punto anti-gene, indicar que el Darwinismo requiere replicadores precisos con poder fenotípico, pero no tienen que ser necesariamente genes».

\section{4. «Memes», virus}

A pesar de las advertencias de Dawkins, el «meme» se ha convertido en un «meme» propiamente tal, una idea que se ha puesto de moda. Pero si existen, ¿cómo viajan, entran en las mentes individuales, y more, 1999: 17). Ella basa sus escritos principalmente en el mecanismo causal de transmisión mética propuesto por Dawkins: la imitación social. Desde su perspectiva, el aprender a copiar las acciones de unos y otros dio a los seres humanos modos superiores de pensar e instaló el estadio para la transmisión y el desarrollo cultural.

El imitador-emisor codifica un mensaje; el receptor-imitador decodifica un mensaje. Las ideas subyacen a las acciones, de manera que la imitación memética tiene contenido, no solo forma. El «meme» actúa simultáneamente como un conjunto de instrucciones para la transmisión cultural y como una unidad de sig. nificado cultural compartido, roles complementarios que se concretan cuando los individuos se comunican entre sí. 
La imitación social construye, empodera y posibilita la diseminación de los «memes» de persona a persona. Pero, la reproducción cultural memética implica más que la trasferencia social de información. La afirmación más científicamente dudosa y controversial acerca de los «memes» es que tienen el potencial de asumir sus propias vidas. Esas ideas que resuenan a través de los sistemas sociales se convierten en elementos culturales que flotan libremente: «memes». Por eso, el «meme» debe ser entendido como un fenómeno sociocultural que se bifurca, que solo puede ser descrito adecuadamente con una definición compuesta: «los 'memes' son ideas culturales que habitan en las mentes de los seres humanos individuales y pasan las ideas de unos a otros, pero que también funcionan independientemente de sus huéspedes humanos». Desde las canciones que usted no puede parar de cantar en su cabeza hasta las fantasías inventadas sobre cielo e infierno, el impacto y el poder de permanencia de elementos culturales particulares dan testimonio de la influencia psicológica y social de los «memes».

Principios de selección subyacen a la transmisión memética. Los mejores imitadores humanos de ideas sobreviven mientras los otros se extinguen (selección natural). La habilidad de imitar o, de modo más general, la destreza comunicativa, se convierte en un criterio clave para escoger machos (selección sexual). Algunos «memes» sobreviven a expensas de otros (selección memética). La tosca similitud entre la replicación genética y la replicación cultural demuestra la potencia de los éstos. Si la evolución biológica puede ser entendida examinando el ADN que ha sido transmitido a través del tiempo, entonces las prioridades culturales deberían revelarse estudiando los temas discursivos y pragmáticos de la vida social que sobreviven. Desde esta perspectiva, los «memes» funcionan como motivadores que comandan la transmisión cultural. Se les podría llamar perfectamente «memes egoístas» (Distin, 2005).

La cultura es un concepto extremadamente impreciso. Los «memes» -los elementos constitutivos de la cultura- deben ser igualmente confusos. Nadie ha visto un «meme» alguna vez. Este solo hecho, no obstante, no debiera sorprendernos o desalentarnos. Nadie había visto un gen hasta que el ADN fue descubierto en la mitad del último siglo. El concepto abstracto de gen había sido anticipado más de cien años antes en los estudios sobre las plantas de arvejas conducidos por el monje agustiniano Gregor Mendel en el entonces Imperio Austríaco. Creyó en algún principio sistémico de particularidad biológica que subyacía a la herencia de las plantas $y$, probablemente, también de los animales. Más tarde, los genes fueron identificados como ese agente y la genética se desarrolló como el sistema que gobierna la herencia de los organismos biológicos. Los científicos aislaron los patrones fenotípicos físicos de la transmisión genética y el mecanismo que crea esos patrones: las extensiones de ADN.

Hasta aquí no tenemos los mismos tipos de percepción y de logros cuando se trata de explicar cómo y por qué algunos rasgos culturales se desarrollan y perduran mientras otros no. Lo más que podemos decir es que los «memes» exitosos sirven como análogos de los genes exitosos en tanto pensamos microscópicamente en los resultados de la transmisión cultural: valores y prácticas ampliamente aceptadas que diferencian de manera clara a un grupo social respecto de otro. Pero los «memes» significan de la manera más amplia.

Un «meme» puede referirse a una minúscula parte de la cultura material -una salsa regional usada para cocinar, por ejemplo- o puede representar la menos material de las dimensiones culturales, la idea de Dios. Los «memes» residen en todo lo que nos rodea e impulsa a pensar y actuar de ciertas maneras. La idea de un vegetal es un «meme», para hablar de un caso, y lo mismo el vegetarianismo. Un envase de aluminio es un «meme», y lo mismo el reciclaje. Una blusa de lino es un «meme», y también la moda. Algunas de las ideas en nuestros mundos y en nuestras cabezas (salsas, dioses, vegetales, vegetarianismo, envases, reciclaje, blusas y moda, por ejemplo) son copiadas con tal frecuencia que se convierten en algo de gran ayuda y persisten en el tiempo.

Como los genes que requieren de un hogar seguro desde el cual operar -la configuración de doble hélice de ADN anidada en un transportador biológico- los «memes» también necesitan ayuda. Requieren de vehículos para ser transportados por todas partes y ayudarles a diseminar su influencia. La noción de un transportador que hospeda y moviliza los «memes», sin embargo, puede no representar adecuadamente la complejidad funcional y la capacidad exigida por el huésped. La transmisión cultural requiere continuos intercambios entre el agente articulador y su medio cultural, de modo que los términos «transportador», «vehículo», o «medio», parecen demasiado limitantes para la tarea. «Interactor» expresa mejor la idea (Hull, 1988; Aunger, 2002).

Un «meme» no solo reside en alguna parte y se moviliza yendo y viniendo sino que también interactúa ventajosamente en contextos culturales que están recargados con otros que compiten por atención. Los más comunes y útiles interactores son las personas. La 
gente adquiere, encarna, transporta, comunica, y da credibilidad a los materiales e ideas culturales a los que hospedan.

Cada artefacto y cada creencia cultural -desde artículos simples como utensilios para comer, marcadores de páginas, zapatos, listas de compras hasta catedrales imponentes, templos, mezquitas y dioses a los que aseguran representar- da forma y transmite múltiples «memes». Por ejemplo, un utensilio de comida alude a tipos de alimento, vida familiar y modos de comer, entre otros significados. Las escuelas, organizaciones religiosas, sistemas políticos, grupos civiles, instituciones mediales, y todas las demás instituciones sociales amparan, sancionan y diseminan una variedad de «memes» abstractos. Los significados culturales habitan en reinos incluso más metafísicos: roles de género, restricciones dietéticas, rituales funerarios, tradiciones folclóricas, teorías académicas, «ad infinitum».

\section{El amplio alcance de la transmisión memética}

Así como los genes funcionan en combinación, en donde los genes individuales se vuelven viables e influyentes gracias a su asociación con otros genes, los «memes» también actúan concertados. Dawkins (2006a: 196-200) se refiere a estas asociaciones culturales que se refuerzan mutuamente como un «memeplex». Por ejemplo, el automóvil pertenece a un «memeplex» que contiene muchos «memes» diversos que tienen que ver con conceptos generales de maquinaria, transporte, libertad, responsabilidad, estilo, licencia y regulaciones, así como marcas, logos, campañas de publicidad y todo lo demás. El automóvil de hoy desciende de la invención de la rueda, el descubrimiento del eje, la fusión de la estructura motriz con el motor a combustión, la industrialización de la línea de ensamble, el refinamiento del petróleo para producir gasolina, y otros hechos. Otro ejemplo familiar $y$ útil es el teléfono. Reconocemos el teléfono como una tecnología de comunicación personal. Pero fue diseñado originalmente como una ayuda en casos de daño en la audición y después se convirtió en una herramienta de vigilancia e información usado en tiempos de guerra. Cada momento cultural permanece en el teléfono actual. Continúa sirviendo como una ayuda para oír, como parte esencial del equipamiento militar y como un medio de comunicación para compartir información, dirigido por el usuario, facilitado por la fibra ópti$\mathrm{ca}$, la tecnología satelital y la industria de las telecomunicaciones planetarias. Remanentes destilados de tipos anteriores como los que están presentes en el automóvil y el teléfono persisten también en el mundo biológico. El hecho ayudó a Darwin a imaginar aspectos cruciales de la descendencia común con modificaciones. La ley darwiniana de la reversión describe cómo el "carácter lejanamente perdido» de generaciones previas aparece en las huellas de los animales en muchas generaciones posteriores (Darwin, 1859/1979: 201). Los artefactos y las ideas culturales nunca tienen éxito solo sobre la base de sus cualidades funcionales. Proyectan significados simbólicos poderosos que acompañan y con frecuencia exceden el significado de cualesquiera fueran los propósitos prácticos que sirven. Cada artefacto y cada idea están anidados dentro de una agrupación de significados potenciales que irradian en todas direcciones a través de la interacción social. La compleja ecología de un «meme» puede ser dominante y limitada al mismo tiempo. La libertad personal, por ejemplo, se hereda como un valor cultural poderoso en automóviles y teléfono pero también han evolucionado severas restricciones en su uso, como parte de sus «memeplexes».

A pesar de las apariencias en contrario, ni los genes ni los «memes» toman la iniciativa o tienen intenciones propias. No obstante, en línea con los principios de selección, evolucionan de modos que les son ventajosos o de lo contrario no existirían. Tal como la saludable diversidad que surge dentro y entre los organismos y las comunidades biológicas, algunos «memes» se vuelven particularmente buenos sobrevivientes en presencia de otros miembros del «memeplex», especialmente cuando están involucrados complicados o controversiales sistemas de creencias. Un conjunto exitoso de genes reside en anfitriones humanos y se perpetúan por medio de la reproducción sexual. Un «memeplex» funciona como una matriz de ideas, costumbres y rasgos que habita en anfitriones humanos y no humanos y transmite su influencia de generación en generación a través de la comunicación humana. Como los organismos biológicos, los «memes» más aptos-aquéllos que atraen la atención más positiva y mantienen su popularidad- sobreviven para afectar a generaciones posteriores.

La forma en que los «memes» y los «memeplexes» esparcen su influencia ha sido comparada frecuentemente con el modo cómo un virus invasivo puede arruinar un cuerpo o una máquina. Desde este punto de vista, los «memes» infectan nuestras vidas. Son contagiosos, parásitos, se introducen en nuestros mundos y controlan cómo vivimos. No hay escapatoria. En "The Meme Machine», Susan Blackmore (1999) sostiene que los algoritmos cognitivos de los «memes» vuelven ilusoria la libertad cultural. La conciencia no existe aparte de la tiranía de los «memes» porque se desarrolla una homología totalizante entre los agentes 
de la reproducción memética y la mente humana. Nos convertimos en los «memes» que nos rodean. Los seres humanos no tienen mentes independientes como para protegernos de los «memes extraños y peligroso» (Dennett, 2006: 342-352).

¿Qué hay de verdad en esto? ¿Somos en realidad víctimas pasivas de la cultura? Las tradiciones y prácticas culturales dominantes enmarcan y guían nuestro pensamiento, con frecuencia de manera inconsciente, y no siempre en nuestro beneficio. Nos socializan para aceptar supuestos culturales básicos y así adaptarnos a conductas y rituales sin cuestionar su historia o los intereses que representan. Emergen triunfadores y perdedores. Sin duda, los «memes» pueden causar daño real a los individuos y a las sociedades. Pero no es un virus cultural el que causa el daño.

La metáfora del «meme-entanto-virus» falla en explicar cómo ocurre la transmisión cultural y cuáles son las verdaderas consecuencias. Los virus solo proporcionan miseria. $\mathrm{La}$ vida cultural, incluso bajo condiciones represivas, no es determinada de la misma manera en que las infecciones virales devastan los cuerpos biológicos o los computadores.

\section{La extensión global de la} transmisión cultural

La comparación de la transmisión cultural con la diseminación de un virus recuerda las teorías habituales sobre el imperialismo cultural y medial. La lamentable historia es bien conocida. Durante siglos, las naciones colonialistas impusieron su voluntad violentamente sobre las regiones menos desarrolladas del mundo, especialmente en África, Asía y las Américas, y luego las saquearon para su propio provecho económico y geopolítico. Las culturas indígenas fueron despojadas. Incluso durante décadas después que la mayoría de las naciones coloniales ganaran su independencia, los colonizadores continuaron ejerciendo su influencia económica, política y cultural y todavía lo hacen. El vertiginoso giro de la globalización asegura que la influencia cultural continúe diseminándose desde las antiguas naciones imperiales -Inglaterra, Francia, España, Portugal, Holanda, Rusia y Japón, especialmente-, pero también desde los Estados Unidos, por supuesto. Las nuevas avanzadas coloniales son imperios de la mente. Corporaciones multinacionales como McDonalds, Disney, Microsoft, Coca-Cola, y Nike, trabajan horas extras para explotar los mercados globales. El patrón de la influencia es vertical. Los medios globales y la tecnología de la información y la comunicación actúan como instrumentos entrecruzados de la opresión cultural contemporánea.

Las teorías del imperialismo cultural y medial coinciden con otra hipótesis nacida en la temprana ciencia social del siglo veinte: los «efectos de los medios» o «los efectos directos». La teoría de los efectos mediales postula que los medios de comunicación de masas arrollan a las audiencias masivas en extendidos procesos de comunicación masiva. Igual como las explica-

\section{La evolución biológica ha creado una insondable colección} de formas de vida desde que la Tierra se formó hace más de seis billones de años. En una fracción más bien minúscula de ese tiempo, el desarrollo cultural se ha instalado en la ciencia moderna, la tecnología, la democracia, las instituciones civiles, incluso en las pequeñas píldoras anticonceptivas y aquellas que prolongan el rendimiento sexual. La naturaleza es información pura: nos provee de recursos interminables. La cultura es conocimiento aplicado; altera lo que la naturaleza nos da. ciones del imperialismo cultural que se basan fuertemente en el Marxismo y la teoría de la sociedad de masas, la relación entre emisores y receptores de mensajes es considerada explotadora y unidireccional. Un estímulo poderoso provoca las respuestas deseadas. La estructura conquista la función. Los medios de comunicación y las industrias culturales corrompen la cultura, contaminan la conciencia, manipulan la conducta y socavan el potencial humano.

Esta manera de pensar tiene sus raíces en la filosofía humanista y la política liberal y merece ser respetada. Las teorías del imperialismo cultural y los efectos mediales fueron desarrolladas para revelar críticamente cómo los medios culturales del siglo XIX estaban influenciando la sociedad. Responsabilizar a los 
medios nunca pasa de moda y el argumento, simple como es, siempre conllevará un elemento de verdad. Pero el paisaje medial ha cambiado tanto en los años recientes que los argumentos que se basan en las realidades del siglo pasado ya no hacen avanzar productivamente el debate. El significativo aumento de la información que circula por el mundo y la explosión de los recursos culturales y las tecnologías de comunicación disponibles para las personas casi en todas partes han cambiado radicalmente la naturaleza de la experiencia cultural.

La audiencia pasiva de los medios de comunicación, si realmente existió alguna vez, desapareció hace mucho. Explicaciones más precisas son las de «audiencia comprometida», "participante», «usuario cultural», o de manera más precisa, el «programador cultural» (Lull, 2007). Los muy expandidos rasgos simbólicos de la cultura actual permiten a los individuos mucho mayor control sobre sus vidas que en el pasado. Cualquier idea sobre individuos o grupos que resultan desesperadamente victimizados por sus experiencias culturales e interacciones distorsiona enormemente lo que está ocurriendo.

La idea del «meme» como un virus y las teorías pasadas de moda sobre el imperialismo y los efectos directos solo connotan las consecuencias negativas de la transmisión cultural (4). Se trata de algo incompleto, tendencioso e, incluso, deshonesto. Charles Darwin también tuvo reflexiones sobre la diseminación de las ideas, pero se centró en la naturaleza positiva y orgánica del proceso. En «The Descent of Man», por ejemplo, escribió sobre cómo los miembros de varios grupos culturales pudieron finalmente superar sus diferencias y empezaron «a mirarlos -a los miembros de otros grupos- como nuestras creaturas compañeras» (Darwin, 1871/1981: 127). La interacción comunicativa hizo esto posible: «Tan pronto como -la preocupación por el bienestar de los otros- es honrada y practicada por algunos hombres, se esparce a través de la instrucción y el ejemplo a los jóvenes, y eventualmente es incorporada a la opinión pública».

La expansión de la información y la opinión a través de la sociedad o la cultura por medio de «la instrucción y el ejemplo», «incorporada en la opinión pública», se asemeja al principio de imitación social de transmisión memética propuesto por Dawkins. Calza también con una tendencia de investigación más reciente: la ciencia del contagio social o ciencia de las redes (Christakis \& Fowler, 2009). Esta aproximación se basa en el modelo de influencia personal de la psicología social estadounidense de mediados del siglo XIX. Los líderes de opinión influyen en el voto y en la conducta de consumo de otros a través de un flujo de información y opinión en dos etapas o varias etapas, que va desde los expertos a los seguidores de temas que van desde consejos de belleza hasta candidatos políticos.

La premisa es evolutivamente sólida: toda la $\mathrm{Hu}$ manidad está interconectada y nuestras acciones, invariablemente, afectan la acción de otros. La explicación de cómo esas acciones de hecho operan, sin embargo, es débil: buenas ideas, malas ideas, estados de ánimo y conductas viajan como los virus, de persona a persona, a veces indirectamente, por medio de un mecanismo no especificado de influencia. Los individuos que constituyen una red social llegan a compartir estados emocionales como la felicidad, rasgos físicos como el sobrepeso, o hábitos personales como fumar. La persona $A$ pudiera influir en la persona $B$ directamente, de manera que ambos individuos llegan a compartir un rasgo. Pero la persona $\mathrm{A}$ pudo influir también en la persona $C$, que está conectada directamente con la persona $B$, incluso si la persona $B$ no es afectada y las personas $A$ y $C$ nunca se conocieron. De este modo, la red tiene alguna clase de misterioso poder propio. En las redes sociales la gente, aparentemente, converge de un modo que excede el poder de cualquier individuo solitario de afectar a otro directamente. De esta forma: ¿qué está operando aquî?, ¿un virus?, ¿un «meme»?, Lla red?

Las explicaciones alternativas del contagio social pueden resultar más satisfactorias que la especulativa teoría de las redes. Gravitamos en personas que ya son como nosotros. La presión de los pares afecta nuestra toma de decisiones más que la llegada de una idea no familiar. Las preferencias y los hábitos personales establecidos pasan por encima de la invasión desde el exterior. Las diferencias de poder interpersonal que se basan en la posición de la familia, la clase social y la jerarquía profesional, con frecuencia vuelven involuntarias las decisiones sobre estilos de vida. Y, por supuesto, la tecnología de información y comunicación interfiere con cualquier efecto directo de red en la vida cotidiana.

Por eso, cualquier idea de transmisión cultural como virus debería dejarse hasta aquí. La magia del contagio social no reside en un virus, ni un «meme», ni en una red. Todas las formas de transmisión cultural tienen algo en común: «son actividad comunicativa operando bajo presión selectiva». El contagio tiene un propósito selectivo de parte de todos los participantes, sea que lo comprendan o no. La comunicación da origen al primer conjunto de genes comunes y a las tribus culturales. Nuestros hábitos fuera de estos conjuntos y 
tribus emanan de y refuerzan las estrategias de sobrevivencia. No estar a tono con nuestros grupos sociales limita nuestra viabilidad, tal como lo vemos todos los días en nuestras vidas personales y profesionales. Hoy, con la capacidad de comunicar a gran distancia literalmente a la mano -el teclado de nuestros celulares y nuestros computadores-, el impulso de conectarse con otros se ha intensificado proporcionalmente. Los límites tradicionales de la intimidad se han ido por el desvío. Los mensajes de texto, el envío de contenidos eróticos, el envío de fotos, el postear los detalles personales de la propia vida, y el «twiteo» de cada instante mundano, son ruegos desesperados por aceptación social con claros motivos evolutivos: sobrevivencia y reproducción.

\section{Naturaleza, cultura y comunicación}

Darwin reconocía el rol de la comunicación en esta clase de desarrollo cultural cuando comparaba cómo la información fluía en sociedades diferentes. El lenguaje del tiempo de Darwin pudiera ofender, pero el asunto sigue siendo el correcto: «En países semicivilizados, con poca comunicación libre, la diseminación del conocimiento será un proceso lento» (Darwin, 1859/1979: 97). Hoy, pasados más de ciento cincuenta años desde que Darwin publicara «El origen de las especies», el programa para el desarrollo de la ONU usa diferentes expresiones para defender la misma idea. Las comunicaciones expandidas y la exposición a un amplio rango de recursos culturales -especialmente las ideas nuevas que llegan de fuera- son fundamentales para el progreso social, particularmente en los países en desarrollo (PNUD 2004).

La idea de que los seres humanos no se han desarrollado biológicamente mucho, desde que nuestros ancestros dejaron África -hace 50.000-60.000 añossimplemente es poco sostenible hoy día. La marcha de la evolución en los pasados 10.000 años ha sido particularmente rápida comparada con cualquier otro tiempo desde que los homínidos se separaron de nuestro ancestro común con los chimpancés hace millones de años (Harpending, 2009). Sin embargo, la evolución biológica permanece relativamente lenta, conservadora e indirecta. No tiene objetivos o interés en el bienestar humano (Wade, 2006: 34). Los motores gemelos de la evolución biológica -la selección natural y la selección sexual- responden gradualmente a mutaciones por azar y dependen de soluciones que crean estabilidad y seguridad.

Por contraste, el desarrollo cultural es rápido, innovador y con propósito. Como un vehículo que acelera de cero a 100 millas por hora, la cultura se puede acrecentar rápidamente. La evolución biológica ha creado una insondable colección de formas de vida desde que la Tierra se formó hace más de seis billones de años. En una fracción más bien minúscula de ese tiempo, el desarrollo cultural se ha instalado en la ciencia moderna, la tecnología, la democracia, las instituciones civiles, incluso en las pequeñas pildoras anticonceptivas y aquellas que prolongan el rendimiento sexual. La naturaleza es información pura: nos provee de recursos interminables. La cultura es conocimiento aplicado; altera lo que la naturaleza nos da. Las trayectorias de la historia natural revelan una distinción crucial. La evolución es acerca de la variación en la naturaleza; el desarrollo es acerca de la innovación en la cultura.

\section{Notas}

${ }^{1}$ El juego «Spore», de Electronic Arts, pudiera ayudar a popularizar el pensamiento evolucionista entre los jóvenes que juegan videojuegos también.

2 Los genes no hacen esto solos. Las moléculas de ácido ribonucleico (ARN) también influyen en el complejo proceso de producción de proteínas.

Richerson y Boyd. El término «patrones culturales internos» proviene de Thomas Sowell, «Race and Culture» (New York: Basic Books, 1994).

3 La excepción a esta crítica de la teoría de los «memes» es Richard Dawkins, el creador del concepto. Las discusiones iniciales y posteriores de Dawkins sobre los «memes» no parecen estar políticamente motivadas.

\section{Referencias}

Aunger, R. (2002). The Electric Meme. New York: Free Press. BLACKMORE, S. (1999). The Meme Machine. Oxford: Oxford University Press.

Christakis, N. \& Fowler, J. (2009). Connected. New York: Little Brown and Company.

DarWIN, C. (1859/1979). The Origin of Species. New York: Random House.

DARWIN, C. (1871/1981). The Descent of Man. Princeton: Princeton University Press.

DAwKINS, R. (1989). The Selfish Gene. Oxford: Oxford University Press.

Dawkins, R. (2006a). The God Delusion. New York: Houghton Mifflin.

Dawkins, R. (2006b). Afterword. Presented to London School of Economics and Political Science. March 16.

DENNETT, D. (1995). Darwin's Dangerous Idea. Evolution and the Meaning of Life. New York: Simon \& Schuster.

DenNeTt, D. (2006). Breaking the Spell. New York: Penguin. DENNETT, D. (2009). Darwin and the Evolution of "Why». Address Given to Darwin Anniversary Festival. Cambridge, UK. July 8. Distin, K. (2005). The Selfish Meme. Cambridge, UK: Cambridge University Press.

GeERTZ, C. (1973). The Interpretation of Cultures. New York: Basic Books.

Harpending, H. (2009). The 10,000 Year Explosion. New York: Basic Books.

HuLL, D.L. (1988). Science as a Process. Chicago: University of 
Chicago Press

Johanson, D. \& EdGAR, B. (2006). From Lucy to Language. New York: Simon and Schuster.

LULL, J. (2007). Culture-on-Demand. Oxford, UK: Blackwell. MAYNARd SMITH, J. E SZATHMÁRY, E. (1995). The Major Transitions in Evolution. Oxford: W.H. Freeman/Spektrum. PinKer, S. \& BLOOM, P. (1990). Natural Language and Natural Selection. Behavioral and Brain Science, 13; 707-784.
Pinker, S. (2009). My Genome, my Self. The New York Times Magazine, January 11;26-30.

RicheRSON, P.J. \& BoYD, R. (2005). Not by Genes Alone. Chicago: Chicago University Press.

United Nations Development Programme (2004). Human Development Report: Cultural.

LiberTY IN TODAY's DiverSE WorLd. New York: Oxford University Press.

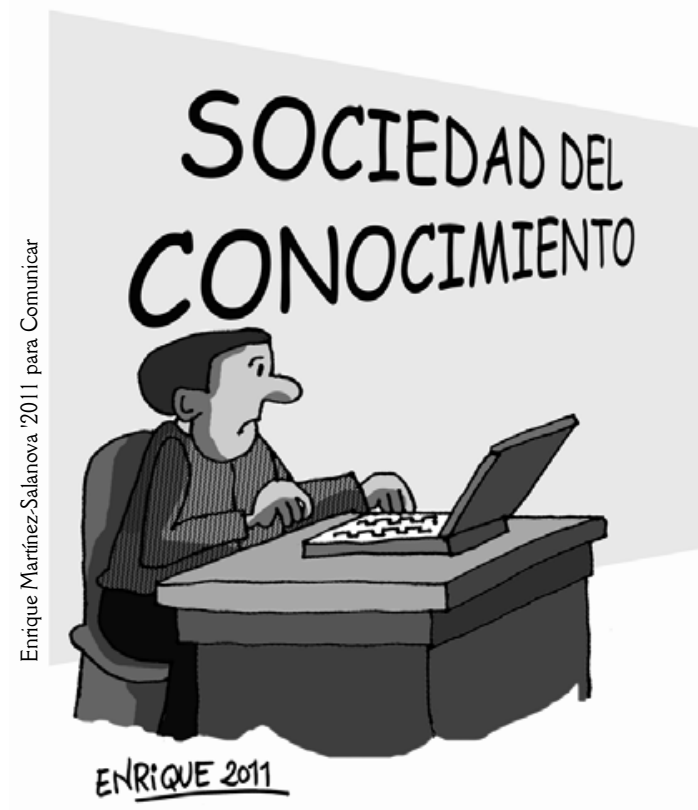

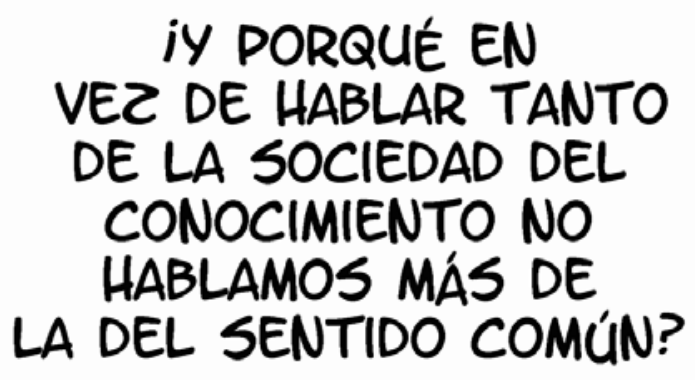

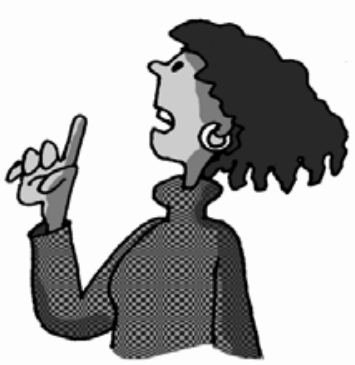

